\title{
Consolidated laser-induced fluorescence diagnostic systems for the NASA Ames arc jet facilities
}

\author{
Jay H. Grinstead ${ }^{1}$ and Michael C. Wilder ${ }^{1}$ \\ NASA Ames Research Center, Moffett Field, CA 94035 \\ Barry J. Porter ${ }^{2}$ \\ AerospaceComputing, Inc., Moffett Field, CA 94035 \\ Jeffrey D. Brown ${ }^{3}$ \\ Analytical Mechanics Associates, Moffett Field, CA 94035 \\ Dickson Yeung ${ }^{4}$ \\ Jacobs Technology, Moffett Field, CA 94035 \\ Stephen J. Battazzo ${ }^{5}$ \\ NASA Ames Research Center, Moffett Field, CA 94035 \\ Timothy R. Brubaker ${ }^{6}$ \\ Pennsylvania State University, University Park, PA 16802
}

\begin{abstract}
The spectroscopic diagnostic technique of two photon absorption laser-induced fluorescence (TALIF) of atomic species for non-intrusive arc jet flow property measurement was first implemented at NASA Ames in the mid-1990s. Use of TALIF expanded at NASA Ames and to NASA Johnson's arc jet facility in the late 2000s. In 2013-2014, NASA combined the agency's large-scale arc jet test capabilities at NASA Ames. Concurrent with that effort, the agency also sponsored a project to establish two comprehensive LIF diagnostic systems for the Aerodynamic Heating Facility (AHF) and Interaction Heating Facility (IHF) arc jets. The scope of the project enabled further engineering development of the existing IHF LIF system as well as the complete reconstruction of the original AHF LIF system. The updated LIF systems are identical in design and capability. They represent the culmination of over 20 years of development experience in transitioning a specialized laboratory research tool into a measurement system for large-scale, high-demand test facilities. This paper documents the overall system design from measurement requirements to implementation. Representative data from the redeveloped AHF and IHF LIF systems are also presented.
\end{abstract}

\section{Introduction}

$\mathrm{H}$ igh enthalpy air arc jet facilities have been essential for the development and validation of thermal protection systems (TPS) for human and robotic space exploration missions since the 1960s. The arc jets at NASA's Ames Research Center offer facility configurations for testing of material samples and subsystems to evaluate thermal and structural performance at flow conditions that simulate the aeroheating environment of atmospheric entry. However, arc jets produce a dissociated gas stream with a chemical composition, temperature, and velocity that dif-

\footnotetext{
${ }^{1}$ Aerospace Engineer, Aerothermodynamics Branch, MS 230-2; Associate Fellow AIAA

${ }^{2}$ Research Engineer, NASA Ames Experimental Aero-physics Branch, MS 260-1; Member AIAA

${ }^{3}$ Aerospace Engineer, NASA Ames Entry Systems and Vehicle Development Branch, MS 229-1

${ }^{4}$ Mechanical Engineer, NASA Ames Thermophysics Facilities Branch, MS 229-4

${ }_{6}^{5}$ Instrumentation Engineer, Engineering Systems Division, MS 213-1

${ }^{6}$ Graduate Research Assistant, Department of Electrical Engineering
} 
fers markedly from the anticipated flight environment. Because critical evaluation of thermal protection material performance depends on transforming test observations into expectations for flight conditions, determining the consequences of these differences is one of the principal challenges in establishing ground-to-flight traceability for cases where gas-surface chemistry is a significant influence on material thermal response. Detailed chemical and physical measurements of arc jet flow parameters could help reduce these uncertainties by establishing a set of boundary conditions upon which the simulations would be anchored. ${ }^{1-3}$

Laser-induced fluorescence (LIF) spectroscopy is a spatially resolved, and nonintrusive means to selectively probe concentrations and energetics of individual atomic and molecular species. The technique is used extensively in laboratory chemical physics applications, especially in applications where conventional contact probes are ineffective or would perturb the measured environment. LIF techniques have been applied for chemistry studies in various arc jet environments, including $\mathrm{H}_{2},{ }^{4} \mathrm{H}_{2}-\mathrm{CH}_{4},{ }^{5} \mathrm{H}_{2}-\mathrm{Ar}-\mathrm{CH}_{4},{ }^{6} \mathrm{~N}_{2}-\mathrm{CH}_{4},{ }^{7} \mathrm{~N}_{2}-\mathrm{CO}_{2},{ }^{8}$ and air. ${ }^{9-20}$ In a LIF measurement of a flowing gas, a laser pulse from a wavelength-tunable laser source excites a specific transition from the ground electronic state in the target atom or molecule; within a few tens of nanoseconds, the excited state relaxes to an intermediate electronic state by emitting a photon. Spectroscopic analysis of the absorbed laser radiation and emitted fluorescence yields quantitative information about the probed species, including initial (or ground) state populations and temperature. Since no physical object contacts the gas, the technique can be used in gases that are at high temperatures and velocities and in highly reactive environments.

For air arc jet flows, significant dissociation in the arc heater followed by rapid expansion in a supersonic nozzle leaves atomic $\mathrm{N}$ and $\mathrm{O}$ as major species in the free stream, and their presence is a sensitive indicator of the degree of chemical nonequilibrium. Quantitative measurements of atomic $\mathrm{N}$ and $\mathrm{O}$ velocity, temperature, and densities with LIF techniques are used to provide insight regarding the thermochemical state of the high enthalpy flow environment present in arc jet testing. The data from LIF measurements can then be used to derive gas dynamic flow properties, stagnation enthalpy, and the distribution of energy over the constitutive modes: kinetic, thermal, and chemical. These data are of value not only for material response testing but also for validating high fidelity CFD simulation tools used for ground test and flight environments. ${ }^{1}$

Both atomic $\mathrm{N}$ and $\mathrm{O}$ can be accessed with two photon absorption laser-induced fluorescence (TALIF), a LIF technique that has become an important tool for combustion and plasma diagnostics in recent years. A development effort that began at Ames in the early 1990s pioneered the application of atomic $\mathrm{N}$ and O TALIF in large-scale arc jet facilities, starting with the $20 \mathrm{MW}$ Aerodynamic Heating Facility (AHF). ${ }^{10}$ A comprehensive experimental capability for quantitative atomic N and O TALIF is now considered state of the art for arc jet diagnostics. Two additional systems were developed and used at NASA in the late 2000s - one for the $60 \mathrm{MW}$ Interaction Heating Facility (IHF) at NASA Ames, ${ }^{16}$ and another for the $10 \mathrm{MW}$ Test Position 2 (TP-2) facility at NASA Johnson Space Center. ${ }^{18}$ Both of these later implementations built upon previous experience from the Ames AHF LIF system. The new systems further expanded performance and efficiency by introducing a calibration source engineered for use in the arc jet facilities, advanced data acquisition instrumentation, and custom data acquisition and instrument control software.

In order to meet testing objectives for NASA's Multi-Purpose Crew Vehicle (MPCV) Orion TPS Project, the agency commissioned an effort to establish two operational LIF diagnostic systems with identical capabilities for the Ames AHF and IHF arc jets. The effort offered an opportunity to address capability and performance gaps in the baseline IHF LIF system completed in 2008. A critical reassessment of validation and calibration requirements led to improvements in the optical configurations, calibration sources, acquisition procedures, and experiment management software. These improvements to the IHF LIF system were replicated in the AHF LIF system, which was completely rebuilt to the new specifications. Both activities proceeded concurrently, and both systems are now in service. The following sections review TALIF for quantitative arc jet flow property measurement, describe the new and updated experimental configurations for the arc jet facilities, and present results from the first post-development demonstration tests.

\section{Arc jet diagnostics with two-photon absorption laser-induced fluorescence of atomic species}

The TALIF processes for atomic $\mathrm{N}$ and $\mathrm{O}$ are shown in Figs 1a) and 1b) respectively. For each process, an atom in the ground electronic state $n_{1}$ simultaneously absorbs two photons from a tunable, pulsed UV laser source. The atom is left in an excited state $n_{2}$ with an energy that equals the sum of the two absorbed photons. Two photon absorption is a resonant third-order nonlinear process, so the absorption probability scales as the square of the incident photon flux. The excited atom in state $n_{2}$ radiates to a lower-lying electronic state $n_{3}$ through emission of an infrared photon, which is collected as the TALIF signal. The absorption and emission characteristics of the TALIF process in an arc jet flow can be related to atomic density, temperature, and velocity. Also shown in Figs. 1a) and 1b) are simi- 


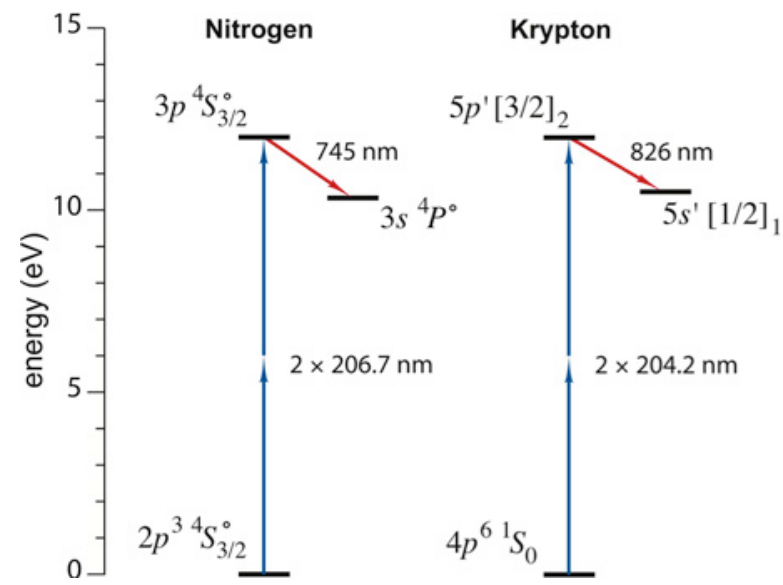

(a)

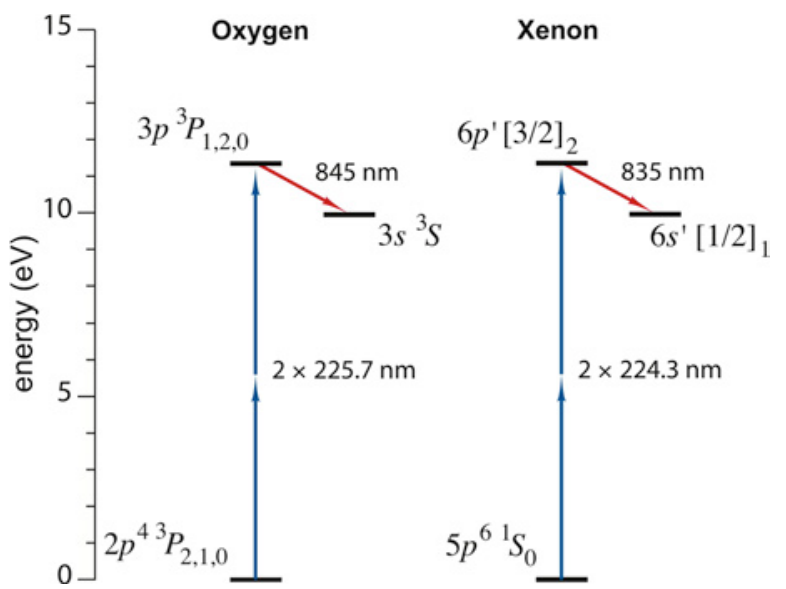

(b)

Figure 1. Two photon absorption and emission processes. a) Atomic nitrogen and its calibration proxy, krypton. b) Atomic oxygen and its calibration proxy, xenon.

lar TALIF processes of $\mathrm{Kr}$ and $\mathrm{Xe}$, respectively, that are resonant at wavelengths adjacent to the $\mathrm{N}$ and $\mathrm{O}$ absorption transitions. TALIF of $\mathrm{Kr}$ and $\mathrm{Xe}$ are used for calibration purposes and will be discussed in more detail in section II.D.

\section{A. TALIF signal modeling}

The theory and rate equation modeling of TALIF provide the means to correlate the observed fluorescence signal magnitude to the absorbing state population, incident laser irradiance, and collisional quenching rate of the laserexcited state. ${ }^{21,22}$ The TALIF signal magnitude as a function of laser wavelength, $S_{L I F}(\lambda)$, can be expressed as the product of the absorbing state particle density, $N_{1}$, and three distinct factor groups arranged in brackets to highlight their influences:

$$
S_{L I F}(\lambda) \propto N_{1} \cdot\left[\sigma_{12}^{(2)}\left(E_{p} / h v A_{p}\right)^{2} \int_{0}^{\infty} F_{p}^{2}(t) d t\right] \cdot\left[g\left(\lambda: \lambda_{0}, \Delta \lambda\right)\right] \cdot\left[\Phi_{23}\right]
$$

The first factor group is the two photon excitation rate integrated over the duration of the laser pulse, where

$$
\begin{aligned}
\sigma_{12}^{(2)} & =\text { Two photon absorption transition cross section } \\
E_{p} & =\text { Incident pulse energy } \\
h & =\text { Planck's constant } \\
v & =\text { Laser frequency } \\
A_{p} & =\text { Cross sectional area of incident beam } \\
F_{p}(t) & =\text { Normalized temporal profile of laser pulse }
\end{aligned}
$$

This collection of terms quantifies the efficacy of the excitation process, where atoms in state $n_{1}$ are excited to the fluorescing state $n_{2}$. The two photon cross section $\sigma_{12}^{(2)}$ is specific to the atom, while the temporal profile $F_{p}(t)$ and cross sectional area $A_{p}$ are characteristic of the incident laser pulse at the measurement location.

The second factor is the normalized excitation lineshape function $g(\lambda)$, which is a convolution of the absorption transition's lineshape and the autocorrelation of the laser spectral profile. ${ }^{23} \lambda_{0}$ is the line center wavelength of the absorption transition, and $\Delta \lambda$ represents the broadening parameters of the excitation lineshape. The absorption lineshape exhibits Doppler broadening due to the translational velocities of the atoms. At higher pressures, the lineshape may also exhibit collisional broadening. The finite spectral bandwidth of the laser will contribute to broadening of the observed excitation lineshape through the convolution.

The third factor, fluorescence yield $\Phi_{23}$, is the ratio of the radiative decay rate $A_{23}$ for the monitored LIF emission to the total depopulation rate of $n_{2}$ from all processes,

$$
\Phi_{23}=\frac{A_{23}}{A_{2}+W_{Q}}=A_{23} \tau_{\text {eff }}
$$


Here $A_{2}=\tau_{0}^{-1}$ is the total radiative decay rate of all allowed single photon emission transitions from the excited state $n_{2}$, and $\tau_{0}$ is the natural lifetime of $n_{2}$. The total non-radiative collisional de-excitation (collisional quenching) rate, $W_{\mathrm{Q}}$, is a function of the quenching partner population densities and quenching rate constants. Collisional quenching diminishes the observed LIF emission magnitude and shortens the lifetime of the excited state. The observed, or effective, lifetime of the excited state is $\tau_{e f f}=1 /\left(A_{2}+W_{Q}\right)$. The fluorescence yield represents the fraction of the laser-excited state population that radiates in the observed emission channel to state $n_{3}$.

Considered as a product, the three factor groups described above quantify the overall efficiency at which the absorbing state population emits photons constituting the LIF signal.

The most important distinction of TALIF is that the signal magnitude scales quadratically with the incident laser irradiance, $E_{p} / A_{p} \cdot F_{p}(t)$. However, multi-photon ionization, amplified spontaneous emission, and ground state depletion are other non-linear laser-induced processes that can occur at high laser irradiances. The observed signal magnitude no longer scales quadratically with incident irradiance if these processes participate. Conformance to quadratic irradiance scaling must be validated experimentally in order to interpret the fluorescence signal magnitude according Eq. (1).

\section{B. Arc jet flow property measurement with TALIF}

A TALIF experimental configuration is comprised of a tunable, pulsed UV laser source, a fluorescence collector and detector, and a means to acquire a time-resolved fluorescence signal as a function of laser wavelength. Figure 2 shows the relevant features of flow property measurement with TALIF in an arc jet facility. A collimated laser beam from a laser source is directed into the facility where it crosses the flow axis at a non-normal angle. The fluorescence collection optics image the intersected region onto a high-gain, high-speed photodetector, such as a photomultiplier tube (PMT). The emitted fluorescence and its temporal decay are recorded with a storage oscilloscope or high-speed digitizer. A tunable laser source enables measurement of the excitation lineshape $g(\lambda)$ by recording the timeintegrated fluorescence as the laser wavelength is scanned over the absorption feature. A curve fit to the measured excitation lineshape determines the peak absorption wavelength $\lambda_{0}$ and line broadening parameters $\Delta \lambda$. The axial flow velocity is proportional to the Doppler shift of the peak absorption wavelength relative to a static reference. The translational temperature of the gas is a function of the lineshape's Doppler line width. The atomic species density is a function of the lineshape's integrated signal magnitude, fluorescence lifetime, and other spectroscopic and experimental factors as described above.

\section{Experimental interpretation of the TALIF signal magnitude}

Measurements of the excitation transition's Doppler shift and lineshape broadening parameters rely only on the relative magnitude of the wavelength-resolved fluorescence signals. Measurement of the observed lifetime, $\tau_{e f f}$, is accomplished through an exponential fit to the time-resolved fluorescence signal decay, which can be of arbitrary magnitude. Measurement of the absolute density of the absorbing state, $N_{1}$, however, does rely on the magnitude of a wavelength- and time-integrated fluorescence signal traceable to a known density in accordance with Eqs. (1) and (2).

Experimental factors that affect the fluorescence signal magnitude must be accounted through direct measurement or calibration or are otherwise known. Excluding the incident laser pulse irradiance, $E_{p} / A_{p} \cdot F_{p}(t)$, those ex-
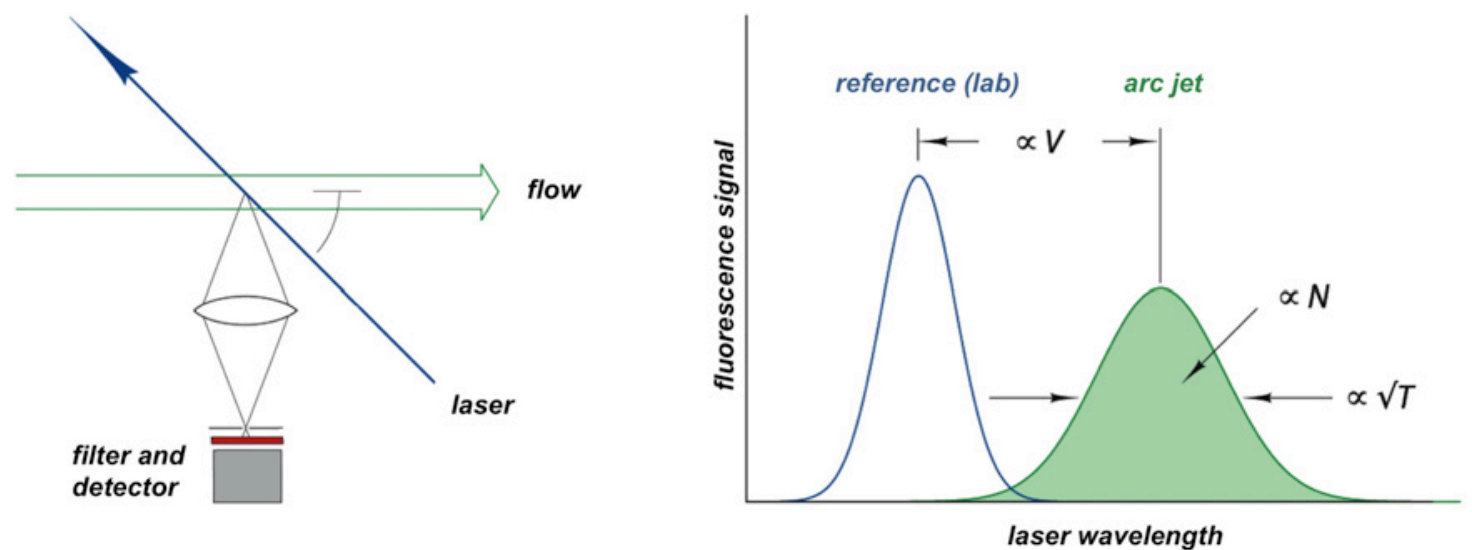

Figure 2. Schematic of arc jet flow property measurement with laser-induced fluorescence. 
perimental factors are defined by the optical configuration and fluorescence signal detection components. The volume of the laser beam segment imaged by the collection optics delineates the spatial resolution of the measurement and constrains the number of atoms illuminated by the laser that can potentially contribute to the LIF signal. The

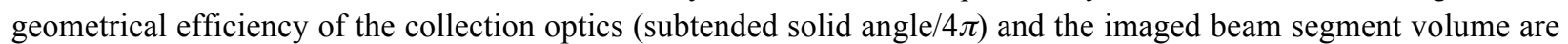
defined features of an experiment configuration. Together they determine the throughput of the imaging system, $G_{\Omega}$. Prior to reaching the photodetector, the fluorescence emitted from the probe volume is discriminated from background emission and laser scatter using spectral filters with a passband at the fluorescence wavelength. To ensure linearity of the photodetector output, a neutral density filter may further attenuate the signal magnitude. The transmission through these filters defines a fraction, $\eta_{f i l t e r}$, of the available photons captured by the imaging system that reaches the photodetector. Finally, the photon flux incident on the photodetector is converted into current, which is then processed by signal recovery electronics into a voltage pulse recorded by a data acquisition instrument. The product of the detector sensitivity and transconductance gain of the signal processing electronics is denoted by $\Gamma_{P M T}$ and represents a linear scaling factor of the photon flux. In practice, $\Gamma_{P M T}$ would be a factor of relative magnitude calibrated as a function of applied gain parameters, such as the high voltage applied to the PMT.

The wavelength-integrated fluorescence signal magnitude, $\bar{S}_{L I F}$, combines Eqs. (1) and (2) with these experimental factors

$$
\begin{aligned}
\bar{S}_{L I F} & =G_{\Omega} \eta_{f i l t e r} \Gamma_{P M T} \int_{\lambda_{1}}^{\lambda_{2}} S_{L I F}(\lambda) d \lambda \\
& =N_{1} \cdot\left[\eta_{f i l t e r} \Gamma_{P M T} \cdot \tau_{e f f} E_{p}^{2}\right] \cdot G_{\Omega} \sigma_{12}^{(2)} A_{23}\left(\frac{1}{h v A_{p}}\right)^{2} \int_{0}^{\infty} F_{p}^{2}(t) d t
\end{aligned}
$$

The integration limits, $\lambda_{1}$ and $\lambda_{2}$, sufficiently capture the isolated excitation lineshape, whose function, $g(\lambda)$, integrates to unity. The collection of terms in brackets is the product of the two experimental measurements $\left(\tau_{e f f}\right.$ and $\left.E_{p}\right)$ and configuration parameters $\left(\eta_{\text {filter }}\right.$ and $\left.\Gamma_{P M T}\right)$ that are known for each excitation lineshape acquisition. Solving for the absorbing state density, $N_{1}$

$$
N_{1}=\frac{1}{G_{\Omega} R_{L} R_{\sigma}} \cdot\left[\frac{\bar{S}_{L I F}}{\eta_{f i l t e r} \Gamma_{P M T} \tau_{e f f} E_{p}^{2}}\right]
$$

where two new factors consolidate the remaining terms from Eqs. (1) and (2),

$$
\begin{gathered}
R_{\sigma} \doteq \sigma_{12}^{(2)} A_{23} \\
R_{L} \doteq\left(1 / h v A_{p}\right)^{2} \int_{0}^{\infty} F_{p}^{2}(t) d t
\end{gathered}
$$

The first, $R_{\sigma}$, contains the only atom-specific spectroscopic terms relevant to the TALIF process. The second, $R_{L}$, has terms related to the laser beam characteristics at the measurement location. These two factors and the imaging system throughput $G_{\Omega}$ are not evaluated directly. Instead they either cancel out or merge into a calibration constant determined through the calibration methodology described in the next section.

\section{Calibration for absolute atomic density measurement in the arc jet free stream}

The most direct and accurate means to calibrate for absolute $\mathrm{N}$ and $\mathrm{O}$ density measurements with TALIF is through the use of a source with known atomic $\mathrm{N}$ and $\mathrm{O}$ densities placed at the measurement location in the arc jet test facility. Maintaining a source of active species requires a pulsed or continuous gas discharge and a means to independently quantify the species densities. The confined space inside the arc jet test chamber and the requirement to accommodate the TALIF optical configuration (excitation beam and collection optics viewing vectors) are realistically incompatible with hosting a powered discharge apparatus with appropriate optical access. A suitable alternative is to apply the approach first reported Niemi, ${ }^{24}$ where similar TALIF processes in $\mathrm{Kr}$ and $\mathrm{Xe}$ allow these gases to serve as inert proxies for $\mathrm{N}$ and $\mathrm{O}$, respectively, for calibration of the complete arc jet TALIF experimental configuration. Both the $\mathrm{N} / \mathrm{Kr}$ and $\mathrm{O} / \mathrm{Xe}$ pairs involve excitation at deep UV laser wavelengths of close proximity, followed by emission at likewise adjacent near-infrared wavelengths (Figs. 1a) and 1b)). The significant benefits for TALIF measurements in a large-scale arc jet facility are that 1) the characteristics of the experimental configurations 
for TALIF measurements of the rare gas and active species pairs are nearly identical, and 2) implementation of a quantifiable reference cell with $\mathrm{Kr}$ or $\mathrm{Xe}$ at the measurement location in the arc jet test chamber is easily achieved.

The $\mathrm{N}$ and $\mathrm{O}$ TALIF measurements in the arc jet facility at unknown conditions are traceable to $\mathrm{N}$ and $\mathrm{O}$ TALIF measurements in a laboratory at known conditions through $\mathrm{Kr}$ and Xe TALIF measurements, respectively, in both locations. This calibration approach requires two complete and functionally identical experimental configurations that utilize the same laser source: 1) in a laboratory, with an associated absolute density calibration source for $\mathrm{N}, \mathrm{O}$, $\mathrm{Kr}$, and $\mathrm{Xe}$; and 2) in the arc jet facility, with its own calibration source for $\mathrm{Kr}$ and $\mathrm{Xe}$. Both experimental configurations are capable of measuring $\bar{S}_{L I F}, \tau_{e f f}$, and $E_{p}$ and quantifying the detector experimental parameters $\eta_{f i l t e r}$ and $\Gamma_{P M T}$ - the terms in brackets in Eq. (4). The link between the laboratory and arc jet configurations is a calibration constant formed with ratios of Eq. (4). Using the $\mathrm{N} / \mathrm{Kr}$ pair as an example of the methodology (the same principle applies to the $\mathrm{O} / \mathrm{Xe}$ pair), the unknown atomic nitrogen density in the $\operatorname{arc}$ jet, $N_{1}^{(\operatorname{arc}-\mathrm{N})}$, can be referenced to the known atomic nitrogen density in the laboratory $N_{1}^{(l a b-\mathrm{N})}$ as

$$
\begin{aligned}
N_{1}^{(a r c-\mathrm{N})} & =N_{1}^{(l a b-\mathrm{N})} \cdot \frac{\left[G_{\Omega} R_{\sigma} R_{L}\right]^{(l a b-\mathrm{N})}}{\left[G_{\Omega} R_{\sigma} R_{L}\right]^{(a r c-\mathrm{N})}} \cdot \frac{\left[\frac{\bar{S}_{L I F}}{\eta_{f i l t e r} \Gamma_{P M T} \tau_{e f f} E_{p}^{2}}\right]^{(\operatorname{arc}-\mathrm{N})}}{\left[\frac{\bar{S}_{L I F}}{\eta_{f i l t e r} \Gamma_{P M T} \tau_{e f f} E_{p}^{2}}\right]^{(l a b-\mathrm{N})}} \\
& =N_{1}^{(l a b-\mathrm{N})} \cdot K_{c a l}^{(\text {lab/arc }-\mathrm{N})} \cdot \frac{\left[\frac{\bar{S}_{L I F}}{\eta_{f i l t e r} \Gamma_{P M T} \tau_{e f f} E_{p}^{2}}\right]^{(a r c-\mathrm{N})}}{\left[\frac{\bar{S}_{L L F}}{\eta_{f i l t e r} \Gamma_{P M T} \tau_{e f f} E_{p}^{2}}\right]^{(l a b-\mathrm{N})}}
\end{aligned}
$$

The superscripts refer to the experimental location ( $\operatorname{arc}$ jet facility or laboratory) and the atomic species. The lab/arc jet calibration constant $K_{c a l}^{(l a b / a r c-N)}$ can be defined from the ratio of the leading amplitude factors,

$$
K_{c a l}^{(l a b / a r c-\mathrm{N})} \doteq \frac{\left[G_{\Omega} R_{L}\right]^{(l a b-\mathrm{N})}}{\left[G_{\Omega} R_{L}\right]^{(\operatorname{arc}-\mathrm{N})}}
$$

The atom-specific spectroscopic factor, $R_{\sigma}$ of Eq. (5), cancels in the ratio as both are for the same atom (N).

The same formulation can be constructed for $\mathrm{Kr}$, the proxy for $\mathrm{N}$. Rearranging terms and solving for its calibration constant,

$$
K_{c a l}^{(l a b / a r c-\mathrm{Kr})} \doteq \frac{\left[G_{\Omega} R_{L}\right]^{(l a b-\mathrm{Kr})}}{\left[G_{\Omega} R_{L}\right]^{(a r c-\mathrm{Kr})}}=\frac{N_{1}^{(a r c-\mathrm{Kr})}}{N_{1}^{(l a b-\mathrm{Kr})}} \cdot \frac{\left[\frac{\bar{S}_{L I F}}{\eta_{f i l t e r} \Gamma_{P M T} \tau_{e f f} E_{p}^{2}}\right]^{(l a b-\mathrm{Kr})}}{\left[\frac{\bar{S}_{L I F}}{\eta_{f i l t e r} \Gamma_{P M T} \tau_{e f f} E_{p}^{2}}\right]^{(a r c-\mathrm{Kr})}}
$$

Following Niemi, ${ }^{24}$ the key assumption of the calibration approach is that $K_{\text {cal }}^{(l a b / \operatorname{arc}-\mathrm{Kr})}=K_{\text {cal }}^{(\text {lab }}{ }^{\mathrm{arc}-\mathrm{N})}$, provided no changes to the experimental configurations affecting $G_{\Omega}$ and $R_{L}$ are made subsequent to evaluation of the calibration constant. All quantities on the right hand side of Eq. (9) can be measured or are known, enabling direct evaluation of $K_{c a l}^{(l a b / a r c-\mathrm{N})}$. The unknown $\mathrm{N}$ density in the arc jet facility can then be computed using this calibration constant and Eq. (7), where all other terms on the right hand side are likewise measured or known.

\section{Laboratory and arc jet TALIF configurations}

The motivation for describing the TALIF process and calibration methodologies in detail was to identify the essential measurements and experimental parameters required to determine the arc jet flow properties of temperature, velocity, and atomic $\mathrm{N}$ and $\mathrm{O}$ species densities. Considering an arc jet TALIF capability as a system, these measurements and parameters constitute primary system design requirements. The guiding principle for rigorous implementation of a quantitative TALIF capability is to ensure that measured values conform to the theoretical relationships or behavioral assumptions applied in analysis - in other words, validation. Providing the means to conduct validation experiments is therefore also a system design requirement. Secondary requirements flowing down from 
these primary requirements drove the design of supporting experiment subsystems, operational procedures, and data acquisition modes. Once conformance to theory has been demonstrated, the measured flow properties can be further applied and analyzed, with justification, in the context of arc jet nonequilibrium aerothermodynamics.

A LIF system for large-scale arc jet flow diagnostics is comprised of a laser laboratory, an optical apparatus incorporated into the arc jet test chamber, and a data acquisition system for recording LIF and laser pulse energy measurements in the laboratory and arc jet test chamber. The LIF laser laboratory houses the pulsed, tunable UV laser source, an absolute atomic $\mathrm{N}$ and $\mathrm{O}$ calibration source, an optical configuration for LIF calibration and ancillary parameter measurements, supporting test instrumentation, and the primary data acquisition/instrument control computer. The optical apparatus for arc jet measurements delivers a beam from the laser laboratory to the probe volume and collects and detects the emitted fluorescence from the probe volume. A portable flow system and reference cell provide for calibration of the arc jet optical configuration using $\mathrm{Kr}$ and $\mathrm{Xe}$.

The following sections describe the major subsystem components of the AHF and IHF LIF systems. The laboratory configuration and capabilities are common to both. The optical implementation for each facility differs due to configuration differences between the facilities.

\section{A. LIF system laser laboratories}

Laser system A pulsed tunable laser source accesses the four two-photon absorption transitions described in Section II. The laser system consists of a tunable dye laser pumped by an injection-seeded, frequency doubled Nd:YAG laser operating at $20 \mathrm{~Hz}$ (Continuum Vista/Powerlite DLS 9020 [AHF] and Continuum ND6000/Powerlite $9020[\mathrm{IHF}]$ ). The dye output is frequency tripled by a pair of auto-tuning beta-barium borate (BBO) crystals (Inrad Autotracker III) to reach the UV wavelengths for TALIF. A single laser dye cannot span the wavelength range needed for the frequency tripled output to access both TALIF transition pairs $(\mathrm{N} / \mathrm{Kr}$ and $\mathrm{O} / \mathrm{Xe})$. For the $\mathrm{N} / \mathrm{Kr}$ pair, a mixture of PM-597 and DCM dissolved in ethanol was used. ${ }^{25}$ The relative mixture concentration was tailored to achieve approximately the same total output power at the two fundamental wavelengths $(620.15 \mathrm{~nm}$ and $612.58 \mathrm{~nm})$. The dye LDS-698 dissolved in methanol was used to reach the O/Xe transition pair near $225 \mathrm{~nm}$. The fundamental dye laser linewidth was approximately $0.04 \mathrm{~cm}^{-1}$ or $1.5-1.8 \mathrm{pm}$. The total laser pulse energy at the four UV TALIF wavelengths was 5-6 $\mathrm{mJ}$ in a $6 \mathrm{~ns}$ pulse.

TALIF optical configuration The laser system, beam path, TALIF calibration source, optical detectors, and beam diagnostics are shown in the schematic of Fig. 3a). The UV laser output is divided into two beams for LIF measurements in the laboratory and arc jet facility, respectively. Each beam path has a means for continuous variation and measurement of pulse energy to characterize the pulse energy dependence of TALIF signals as described in Section II.A. The laboratory (reference) beam directed through the calibration source is split off from the main beam using an uncoated fused silica window that functions as a polarizing beamsplitter. The reflected energy is controlled in a manner similar to a rotating $1 / 2 \lambda$ waveplate/polarizing beamsplitter variable attenuator. The exception is that the front surface of the uncoated window only reflects a maximum of $4 \%$ of the incident S-polarized pulse energy,

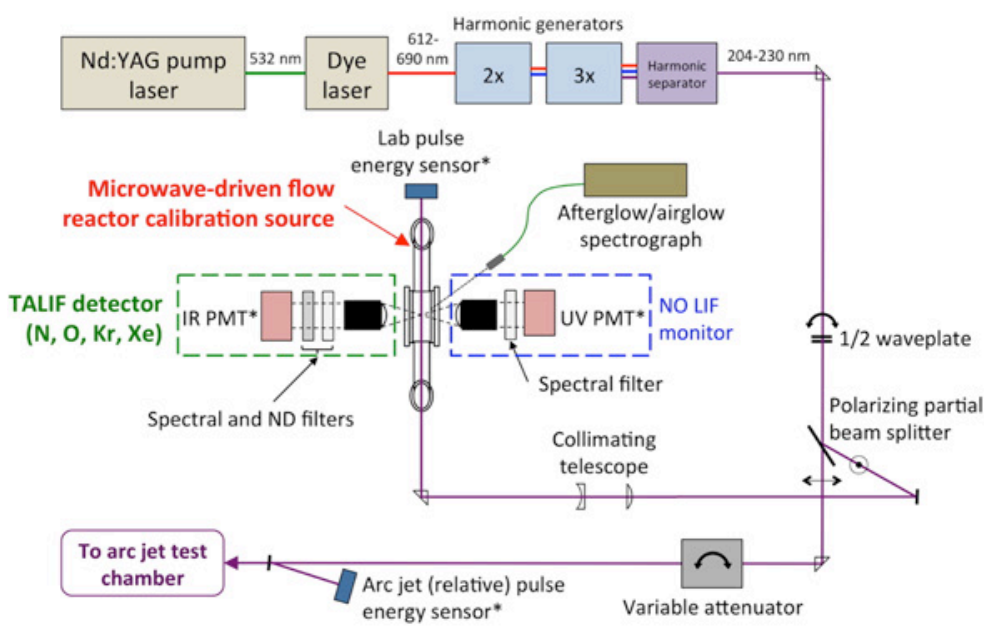

a)

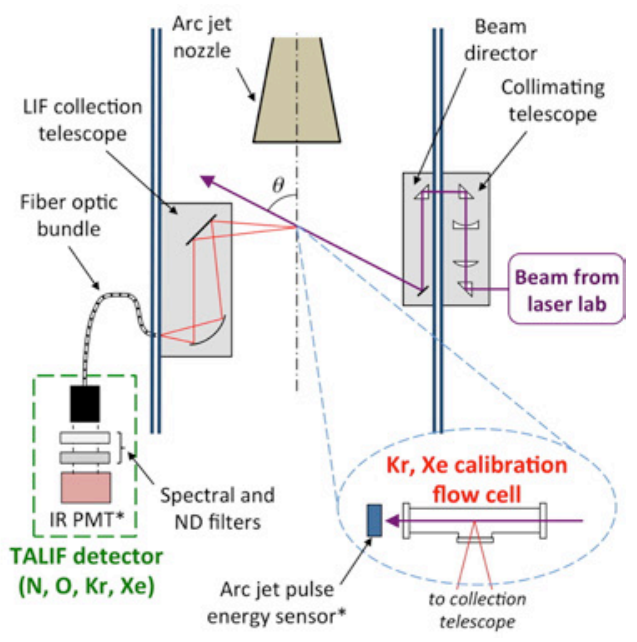

b)

Figure 3. Optical configurations for the a) laser laboratory and b) arc jet test chamber. Signals from sensors and detectors noted with asterisk (*) are recorded by the data acquisition system. 
which is more than sufficient for laboratory TALIF signal characterization and density calibration. The reference beam is collimated to an approximate diameter of $0.5 \mathrm{~mm}$ within the observation region of the calibration source. A pyroelectric energy sensor (Ophir PE25-C) placed at the exit of the calibration source measures the reference beam pulse energy.

The remainder of the main beam enters a high-energy variable attenuator (Newport 935-5), which affords control over the full pulse energy directed to the arc jet test chamber. A second uncoated window, located after the attenuator and placed at near-normal incidence to the beam, reflects a portion of the beam to another pyroelectric energy sensor (Coherent J50) for relative measurement of the incident pulse energy during arc jet operations. All $90^{\circ}$ beam turning optics are fused silica prisms with broadband deep UV anti-reflection coatings (193-248 nm).

Near-infrared TALIF signals from the calibration source are imaged with $f / 2$ optics. A field stop limits the imaged volume to a $3 \mathrm{~mm}$ segment of the reference beam at the center of the calibration source's observation region. The collimated fluorescence is transmitted through two computer-controlled filter wheels (Thorlabs FW102A or FW102C) and refocused on a photomultiplier tube. The first filter wheel has a selection of narrowband filters with pass bands corresponding to the TALIF emission wavelengths. The second filter wheel houses a range of neutral density filters up to nominally OD 3.0. The photomultiplier tube (Hamamatsu R9880U-20) has a red-sensitive photocathode and high gain anode with a 0.6 ns rise time. The photomultiplier current was amplified by an Ortec 9306 dual output $1 \mathrm{GHz}(0.35 \mathrm{~ns}$ rise time) preamplifier. A $500 \mathrm{MHz}$ digital storage oscilloscope (Tektronix DPO5054B) records fluorescence pulse waveforms.

TALIF calibration source The laboratory's atomic species density calibration source provides the means to characterize, with the same optical configuration, the TALIF signals of $\mathrm{N}, \mathrm{O}, \mathrm{Kr}$, and $\mathrm{Xe}$ for the $\mathrm{N} / \mathrm{Kr}$ and $\mathrm{O} / \mathrm{Xe}$ calibration methodology described in Section II.D. The active atomic species, $\mathrm{N}$ and $\mathrm{O}$, are generated through microwave dissociation of $\mathrm{N}_{2}$ and $\mathrm{O}_{2}$, respectively, in a low pressure flow reactor. The absolute $\mathrm{N}$ and $\mathrm{O}$ densities are determined through well-known titration processes with $\mathrm{NO}$ and $\mathrm{NO}_{2}$, respectively. ${ }^{27-28}$ Krypton and xenon are also streamed through the flow reactor under controlled conditions to establish their absolute densities for TALIF calibration.

A schematic of the flow reactor apparatus is shown in Fig. 4. The apparatus is constructed of laboratory glass with fused silica windows for the laser beam transmission and for fluorescence observation from opposite sides of the laser beam path. The laser entrance and exit windows are affixed to the apparatus at Brewster's angle to minimize transmission losses of the S-polarized reference beam. The gas supply and vacuum system enables operation with prescribed volumetric flow rates and pressure through mass flow controllers (MKS 1179A), a mass flow controller programmer (MKS 647C), and a vacuum throttle valve with an integrated pressure controller (MKS 153E). A capacitance manometer (MKS 626B) with a range of 10 torr is used for pressure measurement and feedback to the pressure controller. Metered gas flows are introduced at the end of a lamp tube which is enclosed by a $15 \mathrm{~cm}$ long air-cooled microwave cavity (Opthos McCarroll design). The microwave cavity is powered at nominally $70 \mathrm{~W}$ by a

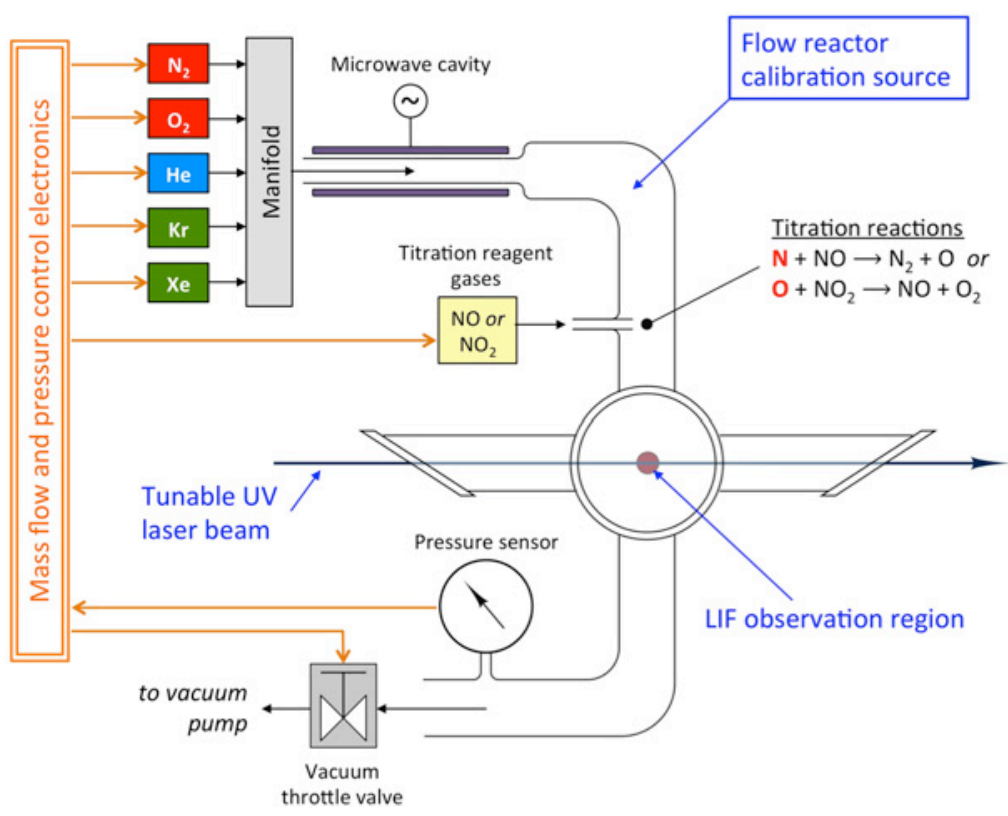

Figure 4. Flow reactor calibration source.
$2450 \mathrm{MHz}$ microwave generator (Opthos MPG-4) for dissociation of the $\mathrm{N}_{2}$ and $\mathrm{O}_{2}$ gas mixtures. The observation region is approximately $25 \mathrm{~cm}$ from the end of the lamp tube. The metered $\mathrm{NO}$ or $\mathrm{NO}_{2}$ reagent gas mixtures are introduced in a mixing chamber approximately $10 \mathrm{~cm}$ upstream of the observation region. A Varian V-81 turbomolecular pump, backed by either a Varian SH-110 scroll or Ebara EV-A03 dry roots pump, evacuates the flow reactor apparatus.

The absolute atomic $\mathrm{N}$ density in a dissociated $\mathrm{N}_{2}$ flow stream of the reactor is determined through titration with NO. The admission of a calibrated flow rate of $\mathrm{NO}$ into the partially dissociated $\mathrm{N}_{2}$ stream initiates the fast exchange reaction $\mathrm{N}+\mathrm{NO} \rightarrow \mathrm{N}_{2}+\mathrm{O}$. At the titration end point, the flux of admitted NO consumes all free $\mathrm{N}$ atoms in the mixing volume, leaving no NO remaining. Or, 
equivalently, the $\mathrm{N}$ flux exactly matches the NO flux admitted into the mixing volume and establishes the means to compute the atomic $\mathrm{N}$ density that exists without the $\mathrm{NO}$ flow introduced into the stream. The absolute $\mathrm{O}$ density of a dissociated $\mathrm{O}_{2}$ stream is determined through titration with $\mathrm{NO}_{2}$, which initiates the exchange reaction $\mathrm{O}+\mathrm{NO}_{2} \rightarrow$ $\mathrm{NO}+\mathrm{O}_{2}$. In this case, the flux of admitted $\mathrm{NO}_{2}$ consumes all free $\mathrm{O}$ atoms, leaving no $\mathrm{NO}_{2}$ remaining. In each titration experiment, the dissociation fraction is a function of the undissociated gas flow rate and reagent gas flow rate at the titration point. The atomic $\mathrm{N}$ or $\mathrm{O}$ particle density is a function of the pressure, temperature, and $\mathrm{N}$ or $\mathrm{O}$ mole fractions computed from the dissociation fraction. The uncertainty of the absolute atomic $\mathrm{N}$ or $\mathrm{O}$ density measurement in the flow reactor calibration source contributes to the overall uncertainty in the atomic $\mathrm{N}$ or $\mathrm{O}$ density measurement in the arc jet facility. That uncertainty, in turn, is influenced by the accuracy with which the reagent gas flow rate at the titration point can be discerned.

The most convenient available means to determine the titration point is to monitor the extinction of the $\mathrm{N}$ or $\mathrm{O}$ TALIF signal while increasing the flow rate of the reagent gas admitted to the mixing volume: the reagent gas flow rate at which the TALIF signal just disappears indicates the titration point has been reached. To improve accuracy in resolving the titration point, a spectrograph observing the reaction region was also implemented to monitor the disappearance of afterglow (for $\mathrm{N}$ determination) or airglow (for $\mathrm{O}$ determination) emission. ${ }^{27,28}$ The afterglow- and airglow-producing reactions involve a reactant of the titration exchange reactions. All emission-producing reactions cease when the atomic species has been consumed, thus signifying that the titration point has been reached. A third means for resolving the atomic $\mathrm{N}$ titration point is to observe the emergence of surplus NO using NO LIF. The NO $B-X(3,0)$ band has rotational excitation transitions in the vicinity of the $\mathrm{N}$ atom TALIF transition at $206.7 \mathrm{~nm}$, enabling observation of NO LIF using the same laser. A second photomultiplier tube with UV sensitivity and a bandpass filter appropriate for discriminating the NO $B-X$ LIF emission was installed on the opposite side of the flow reactor observation window (Fig. 3a)). The extinction of the N atom TALIF signal and the emergence of the NO LIF signal can be observed simultaneously while the NO gas flow rate transits through the titration point.

\section{B. LIF installations in the Ames AHF and IHF arc jet facilities}

The optical configurations for the TALIF systems in the two arc jet facilities had similar requirements: enable quantitative, single point TALIF measurements on the flow centerline at prescribed locations downstream of the nozzle exit plane. A schematic of the arc jet optical configuration is shown in Fig. 3b). The portion of the laser beam from the laboratory is directed through a collimating telescope adjacent to the test chamber. The beam is then injected into the test chamber where steering optics turn the beam to intersect the flow axis at a non-normal angle $\theta$. The TALIF emission from the probe volume is imaged into a fiber optic bundle using an all-reflective telescope mounted inside the test chamber. The armored and thermally insulated bundle passes through a facility port on an adjacent side wall of the test chamber. The fiber bundle output is reimaged onto an integrated detector system placed next to the facility. The detector system has identical specifications to the TALIF detector in the laboratory, including a range of neutral density filters and spectral filters specific to the target TALIF species. The amplified PMT output is directed to the digital storage oscilloscope in the laboratory for fluorescence pulse waveform acquisition.

Calibration of the arc jet optical configuration using the rare gas methodology described in Section II.D relies on a flow cell with optical access placed at the measurement location. The flow cell is a $229 \mathrm{~mm} \mathrm{long,} 76.2 \mathrm{~mm}$ dia. quartz tube with $76.2 \mathrm{~mm}$ dia. fused quartz windows at the ends, a third $76.2 \mathrm{~mm}$ dia. fused quartz window integrated into the side of the tube, and two $6.35 \mathrm{~mm}$ dia. ports for gas inlet and exit. The cell is protected by an acrylic enclosure, and the enclosure can be mounted inside the test chamber such that the cell windows align with the laser beam and fluorescence collection vectors. A pyroelectric energy sensor (Ophir PE25-C) mounted at the exit window of the flow cell measures the pulse energy of arc jet beam. A portable gas supply and vacuum system provides prescribed mixtures of $\mathrm{Kr}$ or Xe buffered with He to the flow cell at specified pressures. The mass flow and pressure control components of the portable system are identical to those used for the laboratory flow reactors.

The optical configurations that were implemented in the AHF and IHF arc jets differ primarily because of the relative locations of the laser laboratories from the corresponding facility test chambers. Figures 5a) and 5b) show the configurations for the AHF and IHF test chambers, respectively. The AHF LIF laser laboratory is located on the floor above and adjacent to a corner of the AHF test chamber. The laser beam exits the laboratory and travels approximately $9 \mathrm{~m}$ to an entrance window on the ceiling of the test chamber. The IHF laboratory is on the same level as the facility test chamber. For safety and accessibility reasons, the laser beam path is elevated with a periscope to approximately $3 \mathrm{~m}$ above the floor for transmission out of the lab to the test chamber. The beam then is lowered and injected into the facility horizontally through a window in the side of the test chamber. The collimating telescopes in each configuration reduce the beam diameter to approximately $1 \mathrm{~mm}$ at the measurement location. Safety interlock systems with engineered controls secure the laser beam transmission paths to prevent exposure of personnel to laser hazards inside and outside of the test chambers. 


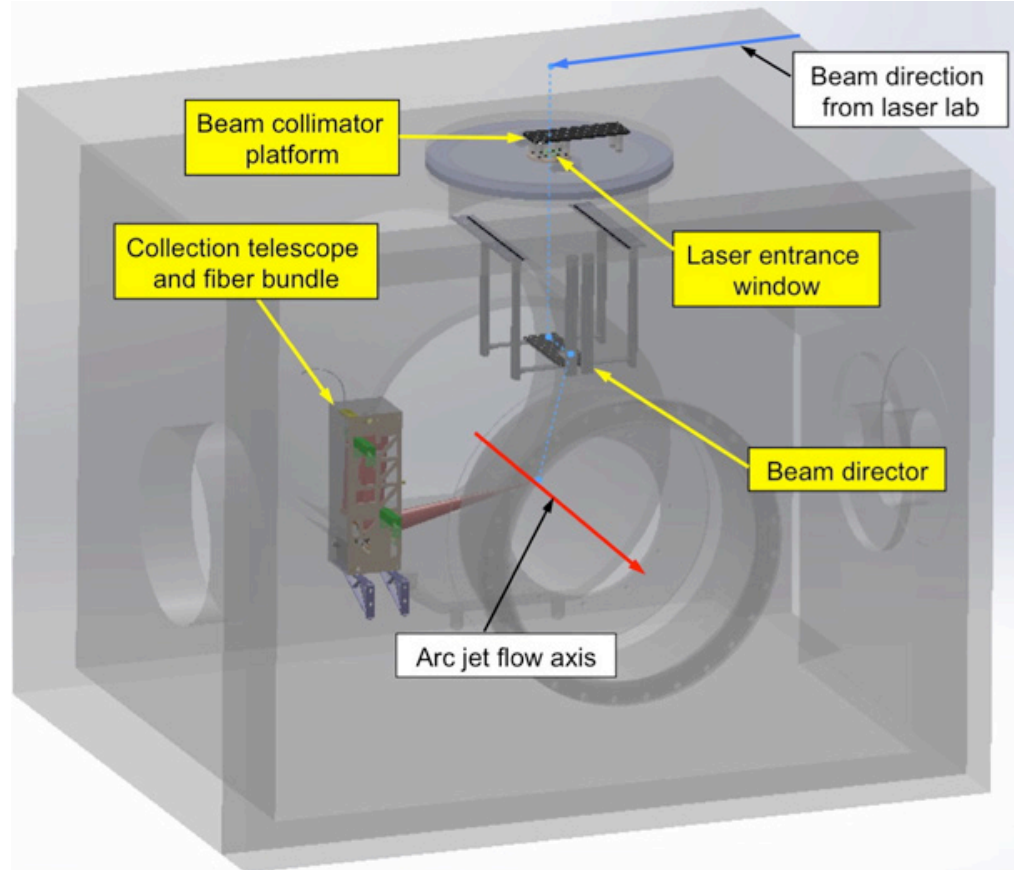

a)

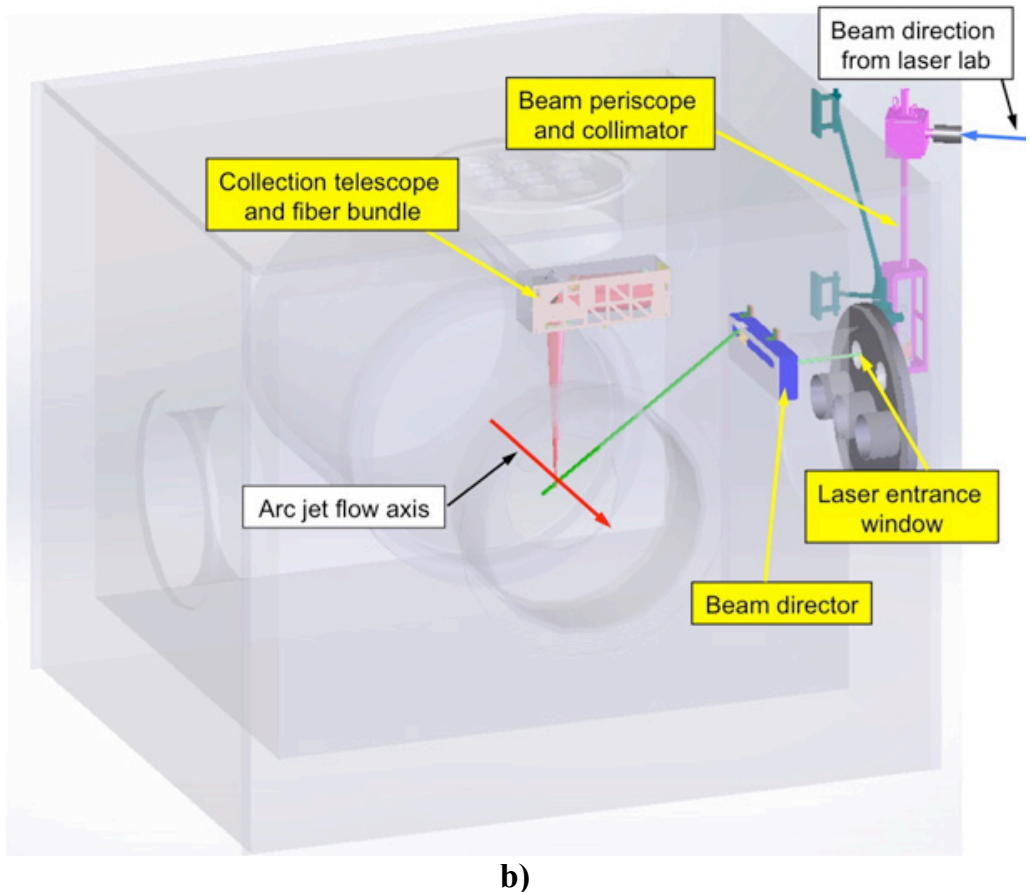

Fig. 5. Arc jet test chamber optical installations. a) AHF facility. b) IHF facility. acquisition and instrument control (DA/IC) hardware and software network was developed to conduct TALIF experiments for testing, calibration, and validation. The primary design requirement for the DA/IC network and operating software was to maximize data acquisition efficiency during arc jet operations. Arc jet facilities are expensive testing resources, and time saved initializing or optimizing experiment parameters prior to data collection reduces the burden on the facility and increases time available for acquisition.

American Institute of Aeronautics and Astronautics

092407

The fluorescence collection telescope, shown in Fig. 6, was designed and fabricated for use in both test facilities. The telescope is a three-mirror folded Herschelian design with a 152 $\mathrm{mm}$ dia. primary mirror. The first flat mirror turns the imaged light by $90^{\circ}$ to the primary. A second flat mirror directs the converging light on to the face of the fiber bundle, which can be positioned axially to adjust the focal distance. One axis of the telescope's first mirror is gimbaled to enable imaging over a range of distances along the flow centerline downstream of the nozzle exit. A black anodized cover with an anti-reflection coated entrance window protects the telescope when installed in the facility. The $f / \#$ of the telescope is approximately 10 with a demagnification of approximately 2 . Figure 6b) shows the telescope installed in the IHF test chamber.

The fiber optic bundle that conveys the imaged fluorescence from the telescope to the detector system contains 155 low-OH silica fibers of 0.39 NA packed into a $5.9 \mathrm{~mm}$ dia. aperture. The bundle is sheathed in a $4 \mathrm{~m}$ long stainless steel monocoil. The bundle exits the facility through a vacuum feedthrough flange occupying an available window port.

\section{Data acquisition and instrument control (DA/IC) hardware and soft- ware}

The TALIF signal analysis and calibration methodology of Section II identified the measurands required to determine absolute atomic $\mathrm{N}$ and $\mathrm{O}$ densities, temperature, and velocity in arc jet flows. The experimental configurations described above implement the means to obtain the necessary calibration and arc jet test measurements. The configurations also enable validation experiments over ranges of input parameters. A comprehensive data
was developed to conduct TALIF exper-

b) 


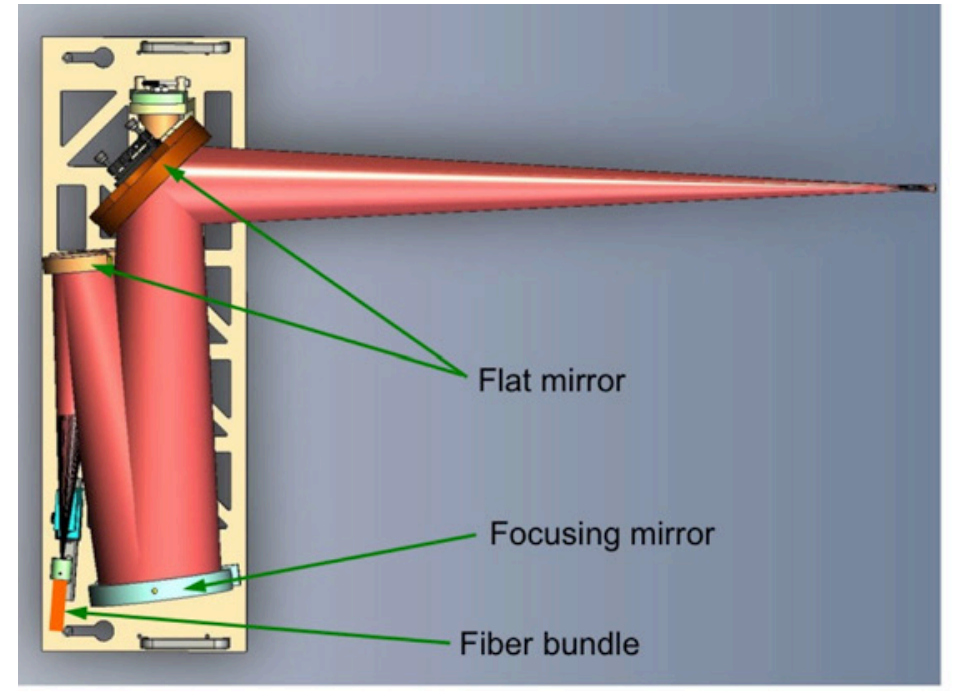

a)
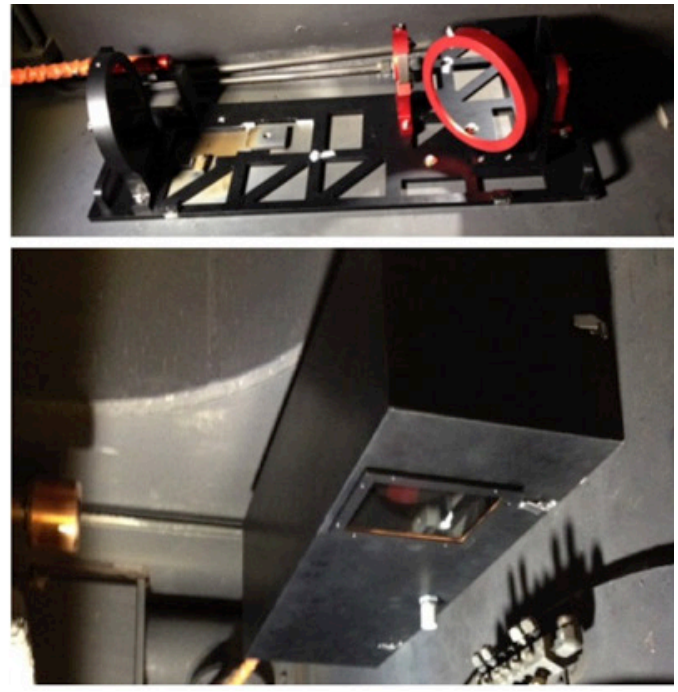

b)

Fig. 6. LIF collection telescope a) Optical configuration. b) Installed in the IHF test chamber with and without protective cover.

The DA/IC computer, located in the laser laboratory, interfaces with the dye laser, flow control electronics, photomultiplier high voltage power supplies, motorized filter wheels, and data acquisition instruments - both for the laboratory and arc jet implementations. The custom-developed LabVIEW and MATLAB software performs most aspects of experiment execution: parameter configuration, data collection, and initial data reduction. LabVIEW configures the test instrumentation, while the MATLAB experiment management program collects data from the acquisition instruments, records instrument parameters, and performs spectral and temporal curve fits. The program then compiles all configuration parameters, data, and user notes into an archive file for subsequent analysis. The laboratory and arc jet TALIF implementations operate simultaneously, so arc jet calibration or test measurements are collected concurrently with the laboratory calibration measurements. Figure 7 summarizes the constitutive parameters and data elements involved in each segment of experiment execution.

The MATLAB program's primary operating mode steps the laser wavelength over a TALIF absorption feature to obtain the reduced excitation scan data listed in Fig. 7. The program's other modes operate at a fixed wavelength, typically at the peak wavelength of the TALIF transition, and acquire fluorescence and pulse energy measurements while sweeping other experimental parameters (pressure, flow rate, or pulse energy). These modes execute validation experiments to assess conformance to TALIF theory and behavioral assumptions. Each of the operating modes accumulates and averages 16 consecutive signal waveforms on the digital storage oscilloscope per experiment step. The laser pulse energy meters simultaneously accumulate a stream of pulses during the same period. The averaged oscilloscope waveforms and pulse energy sensor streams are recorded at each step. For the excitation scan mode, immediate post-experiment data processing yields a time-integrated excitation scan of the absorption feature, a wavelength-integrated temporal waveform of the fluorescence pulse, their spectral and temporal curve fits, and the fit parameters.

The MATLAB program also implements rigorous error checking and data safeguards to prevent loss of data in the event of hardware or software failure during experiment execution.

\section{Data requirements for atomic $N$ and $O$ arc jet flow property measurements}

A complete TALIF measurement campaign for atomic $\mathrm{N}$ and $\mathrm{O}$ arc jet flow property measurements requires data sets from five distinct experiments for each species. Figure 8 shows a list of those data sets and their origin designated by group. The arc jet $\mathrm{N}$ or $\mathrm{O}$ flow velocity and temperature are readily computed from curve fits to the excitation scans acquired simultaneously in the laboratory flow reactor and arc jet facility (group C). All three groups are necessary to compute the absolute $\mathrm{N}$ or $\mathrm{O}$ densities in the arc jet. The density measurement calibration constant for $\mathrm{N}$ or $\mathrm{O}$ is computed with Eq. 9 using their respective rare gas TALIF measurements in the laboratory and facility. In practice, the constants would be determined through regression analyses with multiple $\mathrm{Kr}$ or Xe TALIF measurements over an array of species densities and pressures. Ideally the array of densities and pressures would be chosen to generate TALIF signals that span the available dynamic range of the detector system. The absolute atomic $\mathrm{N}$ or $\mathrm{O}$ densities in the arc jet computed with Eq. 7 would also be determined through regression analyses with multiple $\mathrm{N}$ or $\mathrm{O}$ 


\section{PARAMETER CONFIGURATION}

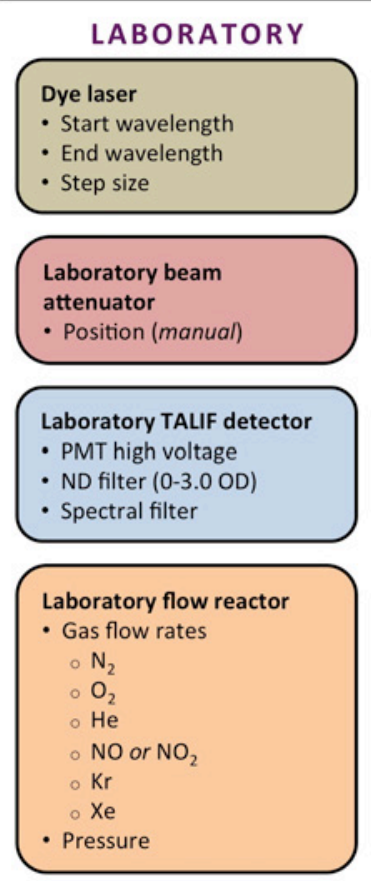

2. DATA COLLECTION

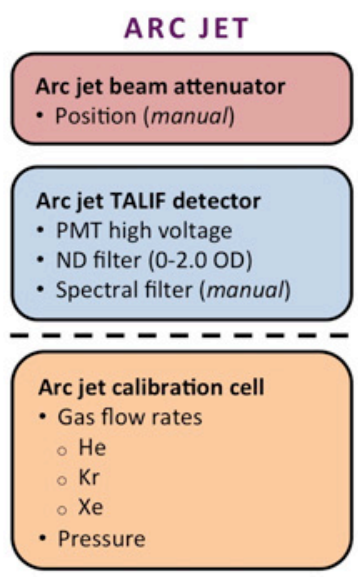

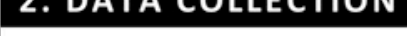

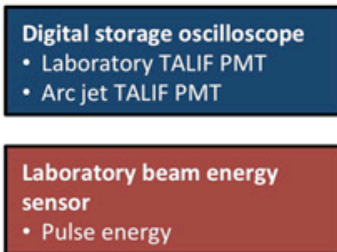

Arc jet relative beam energy sensor

- Pulse energy

Arc jet beam energy sensor - Pulse energy

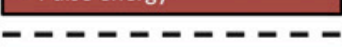

3. DATA REDUCTION

LABORATORY

Excitation lineshape

- Line center

- Line broadening

parameters

Fluorescence pulse

- Effective lifetime

Average pulse energy

Spectrally integrated

fluorescence signal

ARC JET
Excitation lineshape
- Line center
- Line broadening
parameters
Fluorescence pulse
- Effective lifetime
Average pulse energy
Spectrally integrated
fluorescence signal

Figure 7. Instruments, parameters, and measured and reduced data from laboratory and arc jet TALIF experiments. The elements below the dotted lines are configured or acquired only for arc jet facility calibration experiments.

TALIF measurements over an array of species densities and pressures in the laboratory flow reactor. Those absolute densities are determined with the titration methods described in section III.A. The data sets of group B are specific to a single arc jet measurement location (downstream distance from the nozzle exit), while the measurements of group A are not and can be applied to multiple calibration factor determinations. It is important to note that the volume of calibration data (groups $\mathrm{A}$ and $\mathrm{B}$ ) required to obtain absolute $\mathrm{N}$ and $\mathrm{O}$ density measurements at one location in the arc jet far exceeds that acquired during arc-on operations (group $\mathrm{C}$ ).

\section{Demonstration test results}

The LIF development project was provided with testing opportunities in each facility to evaluate the overall performance of the rebuilt AHF and updated IHF LIF systems under arc-on conditions. The specific objectives of these demonstration/verification tests were to assess

- Efficiency of data collection and performance of the DA/IC software

- TALIF signal detectability and performance of the reflective telescope/fiber optic bundle

- $\quad$ Effects of exposure of new LIF hardware inside the test chambers

The IHF tests were conducted in the facility's 6" (152 mm) dia. nozzle. The measurement location was 4" (101 mm)

\begin{tabular}{|c|c|c|c|}
\hline GROUP & NITROGEN & & OXYGEN \\
\hline A & $\begin{array}{l}\text { Laboratory } \\
\text { - N TALIF calibration measurements } \\
\text { - Kr TALIF calibration measurements } \\
\text { - N source densities determination }\end{array}$ & \multirow{3}{*}{$\begin{array}{l}\stackrel{\text { LASER }}{\text { DYE }} \\
\text { CHANGE }\end{array}$} & $\begin{array}{l}\text { Laboratory } \\
\text { - O TALIF calibration measurements } \\
\text { - Xe TALIF calibration measurements } \\
\text { - O source densities determination }\end{array}$ \\
\hline B & $\begin{array}{l}\text { Arc jet - calibration } \\
\cdot \mathrm{Kr} \text { TALIF calibration measurements }\end{array}$ & & $\begin{array}{l}\text { Arc jet - calibration } \\
\cdot \text { Xe TALIF calibration measurements }\end{array}$ \\
\hline C & $\begin{array}{l}\text { Arc jet - test operations } \\
\text { - N TALIF test run measurements }\end{array}$ & & $\begin{array}{l}\text { Arc jet }- \text { test operations } \\
\text { - O TALIF test run measurements }\end{array}$ \\
\hline
\end{tabular}

Figure 8. Summary of data sets required to determine arc jet flow properties of atomic $\mathbf{N}$ and $\mathbf{O}$. downstream of the nozzle exit. The AHF tests utilized the facility's TP-3 arc heater and 7.5" (191 $\mathrm{mm})$ dia. nozzle. The measurement location was 6" (152 mm) downstream of the nozzle exit. The small exit diameters and short downstream distances create higher static pressures at the measurement locations compared to the larger diameter nozzles also used in the facilities. The higher 


\begin{tabular}{|l|c|c|c|c|c|}
\hline $\begin{array}{l}\text { AHF (TP-3 arc heater) } \\
\bullet \\
-7.5 " \text { dia. nozzle } \\
\cdot \mathrm{Z}=6.0^{\prime \prime}\end{array}$ & Arc Current $(\mathrm{A})$ & $\mathrm{N}_{2}$ Flow $(\mathrm{g} / \mathrm{s})$ & $\mathrm{O}_{2}$ Flow $(\mathrm{g} / \mathrm{s})$ & Add Gas $\left(\mathrm{N}_{2}\right)$ Flow $(\mathrm{g} / \mathrm{s})$ & Enthalpy $(\mathrm{MJ} / \mathrm{kg})$ \\
\cline { 2 - 6 } & 1205 & 177 & 71 & 62 & 19.7 \\
\hline
\end{tabular}

Nitrogen
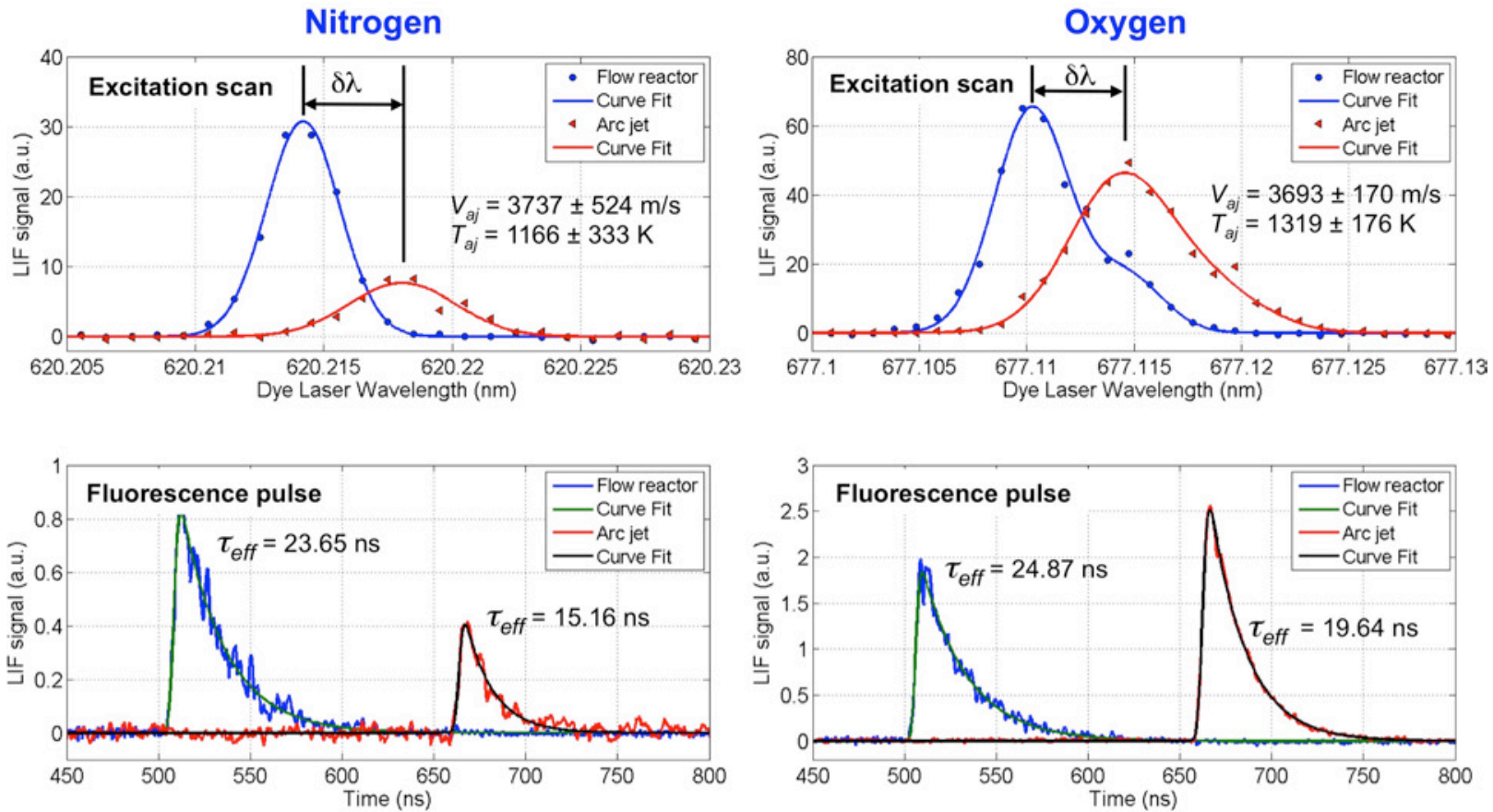

Figure 9. Demonstration test results for the AHF LIF system.

pressures resulted in higher atomic densities but also larger collisional quenching rates that further reduce fluorescence yield. Both $\mathrm{N}$ and O TALIF measurements were collected in each facility during the test series. Test runs were repeated at the same conditions to collect data for the second species following the necessary laser dye change.

The MATLAB experiment management program initialized and executed the laser scans. Prior to executing a scan at each new test condition, the arc jet detector's neutral density filter optical depth and (if necessary) PMT high voltage were remotely adjusted to ensure that the observed peak output voltage from the PMT preamplifier was within its linear range. This step is critical for reducing systematic errors in the acquired signal and was readily completed in less than one minute. The MATLAB program also repeats scans without further configuration or initialization actions by the operator. Typically three laser scans were acquired at each test condition. The total amount of time for signal verification and data collection was approximately 7-8 minutes per condition.

Representative TALIF data from the demonstration/verification tests are shown in Figs. 9 and 10. The plots in Fig. 9 are from the rebuilt AHF LIF system, and the flow parameters for the AHF's TP-3 arc heater are listed in the table at the top of the figure. The stacked graphs are annotated for $\mathrm{N}$ and $\mathrm{O}$ and plot the excitation lineshapes and fluorescence pulses, respectively, acquired in the laboratory flow reactor source and arc jet. Spin-orbit coupling of the ${ }^{3} P$ ground and excited electronic states results in three energy levels, $J "=0,1$, and 2 , of the ground state which couple to three energy levels, $J^{\prime}=0,1$, and 2, of excited electronic state. The excitation lineshape shown in Fig. 9 is a superposition of the three adjacent $J^{\prime \prime}=2 \rightarrow J^{\prime}=0,1$, and 2 transitions. ${ }^{22}$ The laser wavelength step size in the excitation scans was a relatively coarse $0.001 \mathrm{~nm}$ in the laser fundamental wavelength. Each point in the excitation scan is the temporally integrated fluorescence signal magnitude acquired for that step, while the corresponding fluorescence pulse waveform is the average of all the recorded (and previously averaged) pulse waveforms acquired at each laser step. Curve fits to the excitation lineshape and fluorescence pulse are also shown in the plots. The fitted lineshape parameters and known experimental factors enabled immediate estimation of the arc jet flow velocity and temperature and their uncertainties. The effective lifetimes extracted from the fluorescence decay curve fits are also noted in the graphs. The higher temperatures and pressures in the arc jet free stream increase the collision frequency and shorten the effective lifetime of the laser-excited state relative to the 1.0 torr $(0.13 \mathrm{kPa})$ pressure, near-ambient temperature in the flow reactor. The graphs indicate good agreement between the $\mathrm{N}$ and O TALIF measurements of flow velocity and temperature obtained during separate runs on different days.

Data from the updated IHF LIF system, presented in a similar manner, are shown in Fig. 10. This test series was the first for LIF with the 6" dia. nozzle. The facility arc heater parameters are listed above the plots. The IHF test 


\begin{tabular}{|c|c|c|c|c|}
\hline \multirow{2}{*}{\begin{tabular}{|l} 
IHF \\
$\cdot 6 "$ dia. nozzle \\
$\cdot \mathrm{Z}=4.0^{\prime \prime}$
\end{tabular}} & Arc Current (A) & Main Air Flow $(\mathrm{g} / \mathrm{s})$ & Add Air Flow (g/s) & Enthalpy (MJ/kg) \\
\hline & 3500 & 137 & 165 & 27.8 \\
\hline
\end{tabular}

Nitrogen
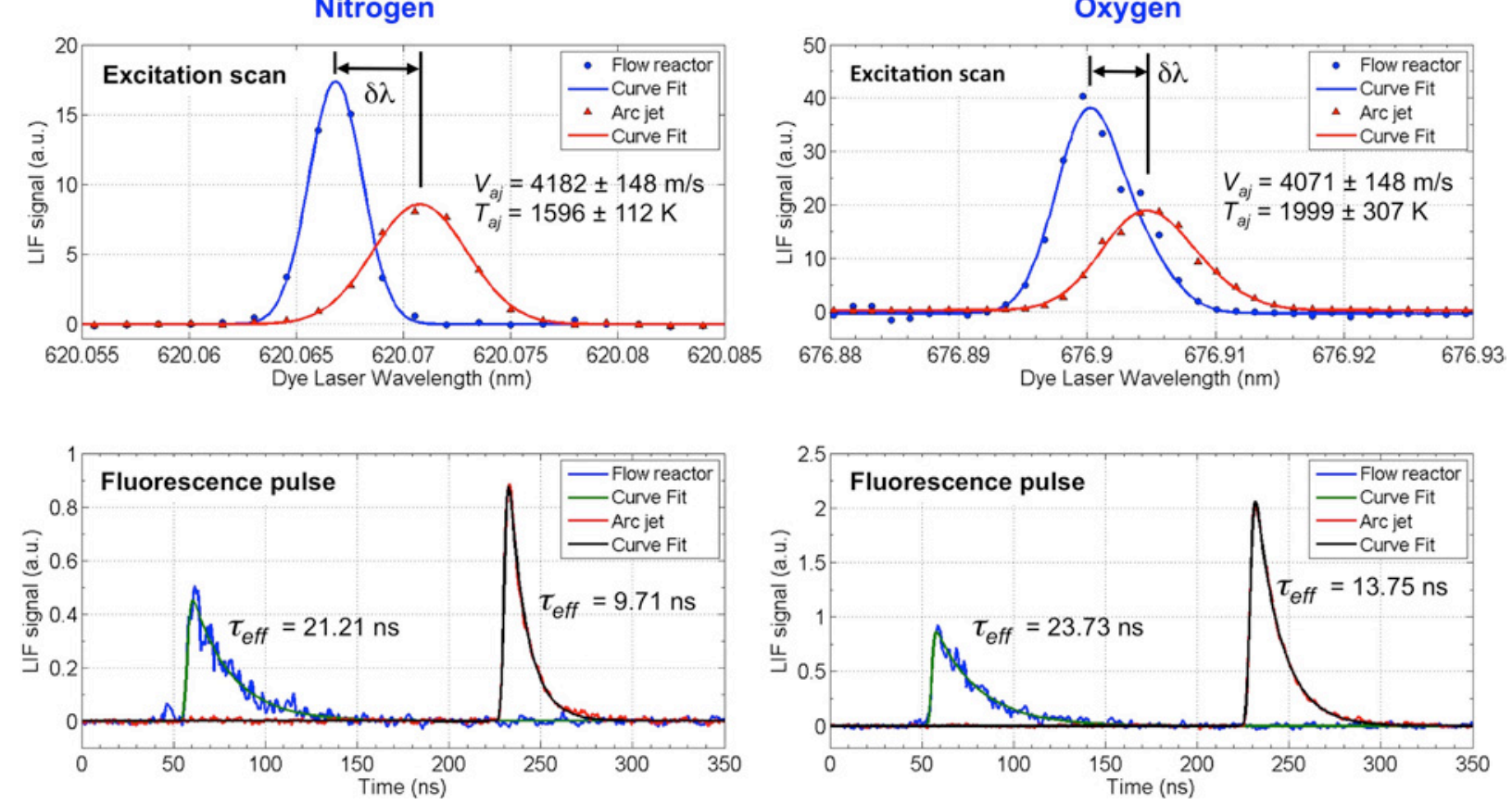

Figure 10. Demonstration test results for the IHF LIF system.

condition reached a significantly higher total enthalpy than that of the AHF test, which resulted in higher velocities and temperatures as evidenced in properties determined from the curve fits. Of particular interest are the much shorter fluorescence lifetimes compared to the AHF results. The observed lifetime for $\mathrm{N}$ at these conditions is approximately $1.5 \mathrm{x}$ the duration of the laser pulse. While the exponential fluorescence decay appears well-resolved here, at even higher pressures and temperatures the de-excitation rates may approach or exceed the laser-induced excitation rate. At that point, it is no longer possible to accurately resolve the decay rate or interpret fluorescence yield (Eq. 2).

Both demonstration tests were the first to use the all-reflective telescope and fiber bundle for arc jet testing. Its function was verified during off-line setup and integration testing with the arc jet calibration cell. The arc-on testing demonstrated that interface and transmission losses with the fiber bundle did not adversely impact TALIF signal sensitivity.

\section{Summary}

The TALIF diagnostic technique for arc jet flow property measurement was first demonstrated over two decades ago in the Ames AHF arc jet. Subsequent development and expansion of TALIF to NASA's other large-scale arc jets at Ames and NASA Johnson Space Center continued over the next several years. Consolidation of NASA's arc jet testing capabilities at Ames in 2013-2014 provided an opportunity to re-examine the existing TALIF implementation in the IHF arc jet while rebuilding the older AHF TALIF system. This review identified performance gaps that led to hardware modifications, development of new data acquisition and instrument control software, and a more rigorous approach to validation and calibration. The outcome of the effort was two operational, state-of-the-art TALIF systems for the Ames AHF and IHF arc jets.

\section{Acknowledgments}

This work was funded by NASA's Office of the Chief Engineer and Strategic Capabilities Assets Program. Additional funding was provided by the Ames Thermophysics Facilities Branch and the NASA Multi-Purpose Crew Vehicle (MPCV) Orion Thermal Protection Systems Project. B. Porter was supported by NASA contract NAS203144 with AerospaceComputing, Inc.; J. Brown was supported by NASA contract NNA01DE12C with ERC Incorporated and NNA15BB15C with Analytical Mechanics Associates; D. Yeung was supported by NASA contracts 
NNA09DB39C and NNA16BD26C with Jacobs Technology. T. Brubaker's summer internship was sponsored by the Ames Education Associates Program. The authors would like to thank M. McGlaughlin, J. Joyce of the Thermophysics Facilities Branch and the test engineers and technical staff of the Ames Arc Jet Complex.

\section{References}

${ }^{1}$ Grinstead, J.H., Stewart, D.A, and Smith, C.A, "High enthalpy test methodologies for thermal protection systems development at NASA Ames Research Center", AIAA paper 2005-3326, May 2005.

${ }^{2}$ Scott. C.D., "Survey of measurements of flow properties in arcjets," Journal of Thermophysics and Heat Transfer, Vol. 7, pp. 9-24, 1993.

${ }^{3}$ Sharma, S.P, Park, C.C., Scott, C.D., Arepalli, S., and Taunk, J., “Arc Jet Characterization”, AIAA Paper No. 1996-0612, Jan. 1996.

${ }^{4}$ Liebeskind, J.G., Hanson, R.K, and Cappelli, M.A., "Laser-induced fluorescence diagnostic for temperature and velocity measurements in a hydrogen arcjet plume," Applied Optics, Vol. 32, pp. 6117-6127, 1993.

${ }^{5}$ Raiche, G.A, and Jeffries, J.B., "Laser-induced fluorescence temperature measurements in a dc arcjet used for diamond deposition," Applied Optics, Vol. 32, 4629-4635, 1993.

${ }^{6}$ Luque, J., Juchmann, W., and Jeffries, J.B., "Absolute concentration measurements of CH radicals in a diamond-depositing dc-arcjet reactor," Applied Optics, Vol. 36, No. 15, pp. 3261-3270, 1997.

${ }^{7}$ Juchmann, W., Luque, J., and Jeffries, J.B., "Two-photon laser-induced fluorescence of atomic hydrogen in a diamonddepositng dc arcjet," Applied Optics, Vol. 44, No. 31, pp. 6644-6652, 2005.

${ }^{8}$ Del Papa, S., Suess, L., and Shafer, B., "The Development of a $\mathrm{CO}_{2}$ Test Capability in the NASA JSC Arc Jet for Mars Entry Simulation," Proceedings of the $8^{\text {th }}$ International Planetary Probe Workshop, Portsmouth, VA, 2011.

${ }^{9}$ Arepalli, S., Yuen, E.H., and Scott, C.D., "Application of Laser Induced Fluorescence for Flow Diagnostics in Arc Jets", AIAA Paper No. 1990-1763, June 1990.

${ }^{10}$ Bamford, D.J., O'Keefe, A., Babikian, D.S., Stewart, D.A., and Strawa, A.W., "Characterization of arc-jet flows using laserinduced fluorescence," Journal of Thermophysics and Heat Transfer, Vol. 9, pp. 26-33, 1995.

${ }^{11}$ Bamford, D.J., and Romanovsky, A., "Velocity and Chemical Composition Measurements in an Arc Jet Flow," AIAA Paper No. 1995-2039, June 1995.

${ }^{12}$ Fletcher, D.G., "Nonintrusive diagnostic strategies for arcjet stream characterization", Measurement techniques for high enthalpy and plasma flows, NATO Research and Technology Organization proceedings RTO-EN-8, 3B-1-3B-37, Neuilly-SurSeine Cedex, France, 2000.

${ }^{13}$ Fletcher, D.G, “Arcjet flow properties determined from laser-induced fluorescence of atomic nitrogen”, Applied Optics. Vol. 38, pp. 1850-1858, 1999

${ }^{14}$ Fletcher, D.G., Bamford, D.J., “Arcjet flow characterization using laser-induced fluorescence of atomic species”, AIAA Paper No. 98-2458, June 1998.

${ }^{15}$ Grinstead, J.H., Driver, D.M., and Raiche, G.A., "Radial profiles of arcjet flow properties measured with laser-induced fluorescence of atomic nitrogen", AIAA Paper No. 2003-400, Jan. 2003.

${ }^{16}$ Grinstead, J.H., Harris, C.L., Yeung, D., Scott, G.P., Porter, B.J., Graube, P., and Greenberg, R.B., "Next-generation laserinduced fluorescence diagnostic systems for NASA arc jet facilities", AIAA Paper No. 2009-1521, Jan. 2009.

${ }^{17}$ Grinstead, J.H., Porter, B.J., Carballo, J.E., "Flow Property Measurements Using Laser-Induced Fluorescence in the NASA Ames Interaction Heating Facility Arc Jet,” AIAA Paper 2011-1091, Jan. 2011.

${ }^{18}$ Scott, C., Suess, L., Milhoan, J., Oelke, L., Godfrey, D., Larin, M., Grinstead, J., and Del Papa, S., "Enthalpy Distributions of Arc Jet Flow Based on Measured Laser Induced Fluorescence, and Heat Flux and Stagnation Pressure Distributions," AIAA Paper No. 2011-3778, June 2011.

${ }^{19}$ Inman, J.A., Bathel, B.F., Johansen, C.T., Danehy, P.M., Jones, S.B., Gragg, J.G., and Splinter, S.C., "Nitric-Oxide Planar Laser-Induced Fluorescence Measurements in the Hypersonic Materials Environmental Test System,", AIAA Journal, Vol. 51, No. 10, pp. 2365-2379, 2013.

${ }^{20}$ Johansen, C., Lincoln, D., Bathel, B., Inman, J., and Danehy, P., "Simultaneous Laser-Induced Fluorescence of Nitric Oxide and Atomic Oxygen in the Hypersonic Materials Environment Test System Arcjet Facility," 17th International Symposium on Applications of Laser Techniques to Fluid Mechanics, Lisbon, Portugal, 7-10 July, 2014.

${ }^{21}$ Adams, S.F., Miller, T.A., "Two-photon absorption laser-induced fluorescence of atomic nitrogen by an alternative excitation scheme," Chemical Physics Letters, Vol. 295, No. 4, pp. 305-311, 1998.

${ }^{22}$ Bamford, D.J., Jusinski, L.E., and Bischel, W.K., "Absolute two-photon absorption and three-photon ionization cross sections for atomic oxygen," Physical Review A, Vol. 34, No. 1, pp. 185-198, 1986.

${ }^{23}$ Feichtner, G.J., and Gord, J.R., "Absorption and the dimensionless overlap integral for two-photon excitation," Journal of Quantitative Spectroscopy and Radiative Transfer, Vol. 68, pp. 543-557, 2001.

${ }^{24}$ Niemi, K., Schulz-von der Gathen, V., and Döbele, H.F., "Absolute calibration of atomic density measurements by laserinduced fluorescence spectroscopy with two-photon excitation," Journal of Applied Physics D, Vol. 34, pp. 2330-2335, 2001.

${ }^{25}$ Wang, W.-B., Chen, D.-Y., Fan, R.-W., and Xlia, Y.-Q., "Spectral Characteristics of PM-597 and DCM Mixture in a Commercial Laser," Laser Physics, Vol. 19, No. 5, pp. 958-960, 2009.

${ }^{26}$ Jennings, K.R., "The production, detection, and estimation of atoms in the gaseous phase, Quarterly Reviews, Chemical Society, Vol. 15, 237-258, 1961. 
${ }^{27}$ Harteck, P., Reeves, R.R., and Mannella, G., "Rate of Recombination of Nitrogen Atoms," Journal of Chemical Physics, Vol. 29, pp. 608-610, 1958.

${ }^{28}$ Reeves, R.R., Mannella, G., and Harteck, P., "Rate of Recombination of Oxygen Atoms," Journal of Chemical Physics, Vol. 32, pp. 632-633, 1960. 